\title{
Higher Concentrations and Ecological Risks of Selected Persistent Organic Pollutants in Macrobrachium lamarrei from the Streams of Sialkot, Pakistan
}

\author{
Rizwan Ullah ${ }^{1}$, Riffat Naseem Malik ${ }^{2}$, Ashiq Muhammad ${ }^{3}$, Karam Ahad $^{3}$, Muhammad Tariq ${ }^{4}$, Rehana Asghar ${ }^{4}$ \\ and Abdul Qadir 5 \\ 1. Department of Zoology, Mirpur University of Science \& Technology (MUST), Mirpur-10250 (AJK), Pakistan \\ 2. Department of Environmental Sciences, Quaid-i-Azam University, Islamabad 45320, Pakistan \\ 3. Ecotoxicology Research Programme, Institute of Plant and Environmental Protection, National Agricultural Research Centre \\ (NARC), Islamabad 44000, Pakistan \\ 4. Department of Biotechnology, Mirpur University of Science \& Technology (MUST), Mirpur-10250 (AJK), Pakistan \\ 5. College of Earth and Environmental Sciences, University of the Punjab, Lahore 54590, Pakistan
}

\begin{abstract}
Persistent organic pollutants (POPs) persisting in the environment, which accumulate in human and animal tissue and bio-magnify in food-chains, would have significant impacts on human health and the environment. Thus, the present study was designed to investigate the accumulation of organic pollutants in prawn from streams of Sialkot, Pakistan. Fresh water prawn Macrobrachium lamarrei was captured from streams of study area. Samples were prepared for extraction of selected organic pollutants and then analyzed through gas chromatograph-electron capture detector (GC-ECD). Results of current study showed that five pesticide residues, i.e., B-HCH, Lindane, DDD, 2, 4-DDT and 4, 4-DDT were detected in composite prawn sample. The rest of POPs residues were not found in prawn. The ratio of $\alpha-\mathrm{HCH} / \gamma-\mathrm{HCH}$ indicated an input of technical $\mathrm{HCH}$ and long range transport, while the ratio of DDT/(DDD + DDE) showed recent use of DDT to the study area. The high values of TEC-HQ and PEC-HQ of POPs in the studied prawn samples depicted risk posed to health.
\end{abstract}

Key words: Prawn, streams, pesticides, Sialkot, Pakistan.

\section{Introduction}

Persistent organic pollutants (POPs) are a variety of synthetic organic compounds that persist in environment, human adipose tissue and animal bodies for long times [1] and resist degradation by biological, photolytic and chemical means. Hence, they accumulate in food webs and pose a risk for human health and environment [2]. Widespread types of POPs are polychlorinated biphenyls (PCBs), polybrominateddiphenyl ethers (PBDEs), polycyclic aromatic hydrocarbons (PAHs), organochlorine pesticides, such as dichlorodiphenyltrichloroethane

Corresponding author: Rizwan Ullah, Ph.D. student, research field: environmental toxicology.
(DDT) and its major metabolitedichlorodiphenyldichloroethylene (DDE), and hexachlorobenzene (HCB) which can be detected in environment and bodies of organisms [3]. Contaminated fish, meat and dairy food products are the primary sources of exposure in the general population [1]. In addition, inhalation from indoor air and ingestion of dust has been suggested to be other important sources of PCB exposure [4]. Despite a ban on the use of PCBs and DDT decades ago, these pollutants are still detectable in environment [5]. Animal studies have suggested that exposure to POPs may induce abdominal obesity, impair insulin sensitivity [6] and reduce glucose uptake [7]. Although there are a few natural sources of POPs, the 

Macrobrachium lamarrei from the Streams of Sialkot, Pakistan

most are created by humans in industrial processes. They enter into the environment through discharges from industrial chemical plants and agricultural spraying, losses from the many consumer products, such as, computers, paints and household products, transport by air and water, and may travel to aquatic ecosystem [8]. Most of POPs in Pakistan are being used in industries and agricultural fields [9]. A large amount of these pesticide reach streams and rivers through sewage discharges, such as, pesticide runoff from farmyards $[10,11]$. The presence of pesticides in rivers can be linked to agricultural use $[12,13]$. The presence of these POPs in aquatic ecosystem affects the target as well as several non-target organisms [14]. Water soluble pesticides enter the aquatic organisms either through body surface or gills or mouth and enter in the food web [15]. The route of entry of pesticides and duration of exposure has substantial impact on their absorption, distribution and biotransformation [16]. These toxic residues reach at high trophic levels because of their biomagnifications property. Prawn (Macrobrachium lamarrei) is on the top of food web in the water ecosystem and has been known to accumulate POPs in significant amounts. POPs associated with sediments produce narcotic effects in benthic organisms and involve in tumor formation in bottom feeding fish, and also involve in fertility loss, malformation induction or immune-deficiency in many organisms [17]. These POPs penetrate into the aquatic population and pose a menace to human health by food [18]. Gewurtz et al. [19] reported that use of shellfish contaminated with PAHs may cause lung cancer in humans. This study was undertaken to analyze the presence of $11 \mathrm{POPs}$, i.e., $\mathrm{B}-\mathrm{HCH}$, Lindane, Heptachlore, H-Exoepoxid, H-Endoepoxid, Endrin, Dieldrin, DDD, DDE, 2,4-DDT and 4,4-DDT in Macrobrachium lamarrei from the two major tributaries of Chenab river, Sialkot district, which is an unplanned industrial city of Pakistan. The population inhabited in the area consumes Macrobrachium lamarrei as a source for food.
Despite the official ban of the above mentioned pesticides in Pakistan, these are still available in the market. Most pesticides are imported as ready-to-use products or technical materials for local formulation [9]. Therefore, analyzing the ecological risk of POPs is crucial for protecting human health and marine environment security. The present study was designed to quantify the level of selected POPs in Macrobrachium lamarrei from stream water of Sialkot, to assess the ecological risk and to monitor the spatial distribution of POPs in area under this study.

\section{Methods}

\subsection{Study Area}

The two tributaries of Chenab river of Sialkot district known as Nullah Aik and Nullah Palkhu, located at $32^{\circ} 24^{\prime}-32^{\circ} 37^{\prime} \mathrm{N}$ and $73^{\circ} 59^{\prime}-75^{\circ} 02^{\prime} \mathrm{E}$, were selected for the present study. These tributaries of Chenab river originate from Pir Panjal range in the state of the Jammu and Kashmir, and then enter in alluvial plain of Punjab as shown in Fig. 1. These streams run parallel from east to west and join to each other before falling in Chenab downstream of Wazirabad city in Gujranwala district. Both tributaries receive pesticides through runoff from agricultural fields and their catchments areas where pesticides are being used. Industrial discharge also adds some of the POPs in these tributaries.

\subsection{Sampling and Preservation of Prawn}

To quantify the selected POPs, including B-HCH, Lindane, Heptachlore, H-Exoepoxid, H-Endoepoxid, Endrin, Dieldrin, DDD, DDE, 2,4-DDT and 4,4-DDT in Macrobrachium lamarrei, 14 sites located on Nullah Pulkhu and Nullah Aik were selected. Among these sites, four were located in upstream and 10 sites were in downstream. For this purpose, spatial sampling of Macrobrachium lamarrei was conducted during April 2010, when streams discharge was between $24,771.58 \mathrm{~m}^{3} / \mathrm{h}$ and $26,708.45 \mathrm{~m}^{3} / \mathrm{h}$. Prawns 


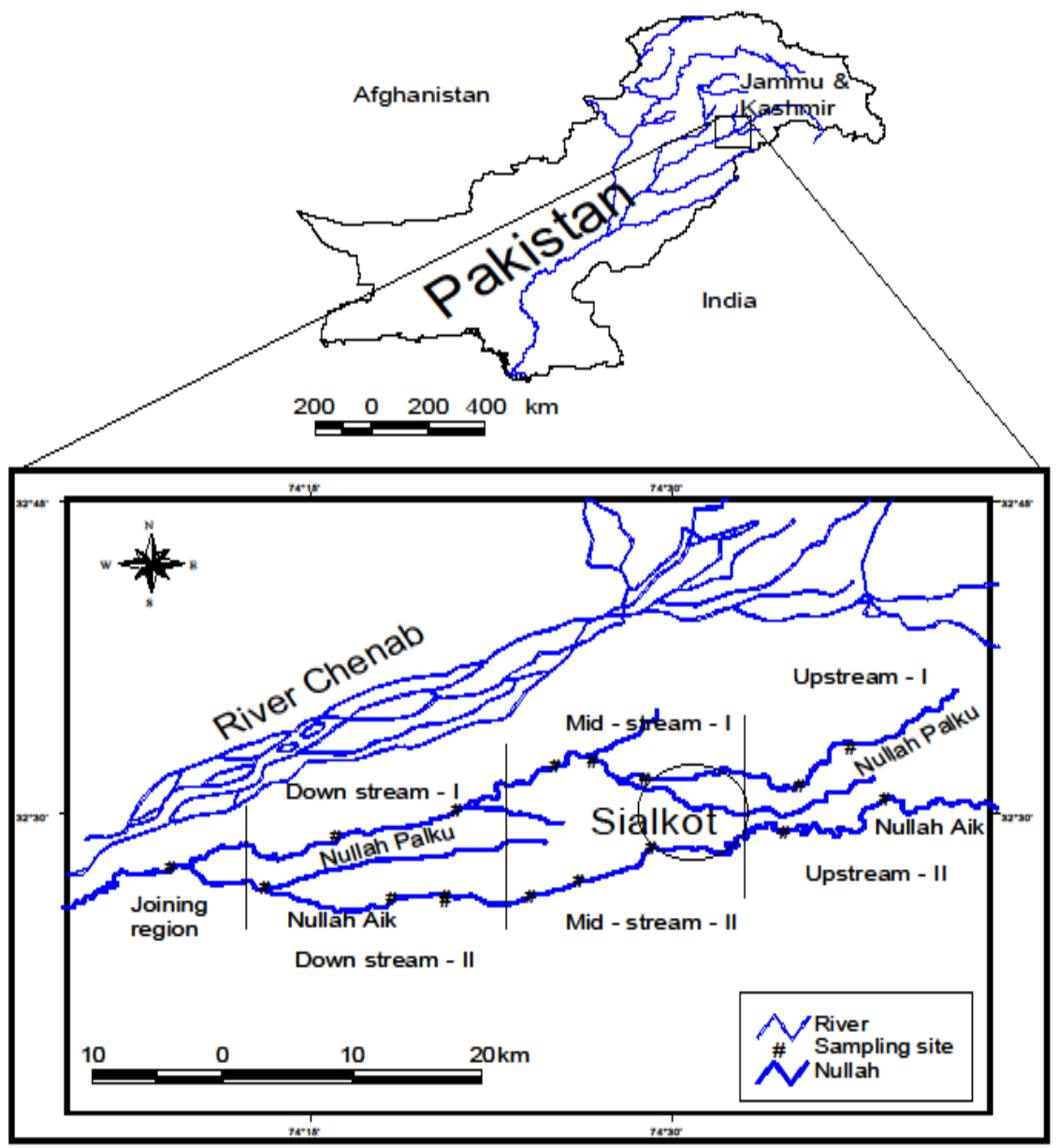

Fig. 1 Plot of Macrobrachium lamarrei sampling locations in Sialkot district on Nullah Aik and Nullah Palkhu.

were sampled by using Penaeid trap net of mesh size of $36 \mathrm{~mm} \mathrm{[20]} \mathrm{and} \mathrm{were} \mathrm{identified} \mathrm{following} \mathrm{the}$ methods described by Sharma and Subba [21]. All collected specimens of prawn were separately wrapped in aluminum foil and transferred in iceboxes to transport in Environmental Biology Laboratory, Quaid-i-Azam University, Islamabad, Pakistan. All specimens were stored at $-20{ }^{\circ} \mathrm{C}$ before further analysis.

\subsection{Extraction}

Whole prawns were used for chemical analysis [10]. Specimens were lyophilized, grinded and homogenized. Composite pools of three or more individuals were analyzed. Then, $2 \mathrm{~g}$ of prawn powder and $\mathrm{Na}_{2} \mathrm{SO}_{4}$ were homogenized and extracted with 6 $\mathrm{mL}$ of $\mathrm{n}$-hexane. For each extraction, $2 \mathrm{~mL}$ solvent mixture was shaken for $2 \mathrm{~min}$ at vortex, followed by centrifugation at 3,000 rpm for $5 \mathrm{~min}$. At the end of extraction, solvent was collected in a test tube and cleaned with $95 \% \mathrm{H}_{2} \mathrm{SO}_{4}$ by shaking at vortex for 2 min, followed by centrifugation at 3,000 rpm for 5 min. Finally extraction solvent was collected as supernatant over $95 \% \mathrm{H}_{2} \mathrm{SO}_{4}$ and evaporated on a rotavapor at $40{ }^{\circ} \mathrm{C}$ under vacuum and optimum rotation speed. Nitrogen stream was used for complete dryness of solvent. Contents were reconstituted in 1 $\mathrm{mL}$ of ethyl acetate and stored in $1.5 \mathrm{~mL}$ gas chromatograph (GC) auto sampler septa voile (Amber Glass) for further chemical analysis on electron capture detector (GC-ECD).

\subsection{Analysis of POPs by Gas Chromatography}

A Perkin Almer auto system equipped with an 

Macrobrachium lamarrei from the Streams of Sialkot, Pakistan

electron capture detector $\left(\mathrm{ECD}-\mathrm{Ni}^{63}\right)$, capillary column (P.E. No. N931-2414, methyl 10\% phenyl silicone, $17 \mathrm{~mm}, 0.32 \mathrm{~mm}$ inner diameter, $0.5 \mathrm{~mm}$ outer diameter, $0.5 \mu \mathrm{m}$ film thickness) and

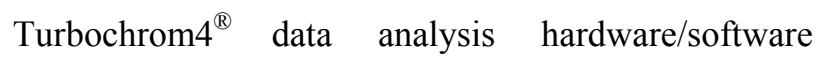
system was used. Moreover, a nitrogen generator (Peak Scientific) was also used in this study. The analytical pesticides standards were purchased from Riedel-de Haen AG Seelze, Germany. All chemicals, solvents and reagents used in this study were all of analytical grade. During the analysis, the injector (splitless mode) and detector temperature was kept at $225{ }^{\circ} \mathrm{C}$ and $300{ }^{\circ} \mathrm{C}$, respectively. Initial oven temperature was set at $100{ }^{\circ} \mathrm{C}$, which was held for 5 min and ramped to $160{ }^{\circ} \mathrm{C}$ at a rate of $15{ }^{\circ} \mathrm{C} / \mathrm{min}$ to $190^{\circ} \mathrm{C}$ at the rate of $2{ }^{\circ} \mathrm{C} / \mathrm{min}$. The backup pressure of carrier gas $\left(\mathrm{N}_{2}\right)$ was kept at 12 psi. The carrier flow rate was kept at $10 \mathrm{~mL} / \mathrm{min}$, whereas pressure of makeup gas $\left(\mathrm{N}_{2}\right)$ was $32 \mathrm{~mL} / \mathrm{min}$. The total run time for the analysis was $19.5 \mathrm{~min}$. Besides, $1 \mu \mathrm{L}$ of the standard/sample was injected with a $10 \mu \mathrm{L}$ Hamilton syringe by the solvent flush injection technique. POPs were identified in prawn on the basis of retention time and quantified on the basis of their peak area by external standard method. The total concentration of POPs was calculated as a sum of individual congener concentrations. The recoveries of selected pesticides (POPs) were calculated on the base of no further changes/or addition on anything made in recovered material.

\subsection{Compositional and Isomeric Ratio Analysis for} Possible Sources

Variations in the composition of isomers of $\mathrm{HCH}$ or DDT found in the environment could be used to point out various contaminating sources [22].

\subsubsection{HCHs}

Broad spectrum pesticides used for agricultural purposes contain technical $\mathrm{HCH}$ and it has been banned in Pakistan since 1993. There are four principal isomers of technical $\mathrm{HCH}: \alpha-\mathrm{HCH}$
(60\%-70\%), $\beta$ - $\mathrm{HCH}(5 \%-12 \%), \gamma-\mathrm{HCH}(10 \%-15 \%)$ and $\delta$ - $\mathrm{HCH}(6 \%-10 \%)$, while Lindane has $>99 \%$ of $\gamma-\mathrm{HCH}[23,24]$. The $\alpha-\mathrm{HCH} / \gamma-\mathrm{HCH}$ ratio has been used to identify the possible $\mathrm{HCH}$ source. If the ratio of $\alpha-\mathrm{HCH}$ to $\gamma-\mathrm{HCH}$ is higher than 3, it indicates the input of technical $\mathrm{HCH}$ and long range transport [25]. However, a ratio close or $<1$ is characteristic of lindane sources [26, 27].

\subsubsection{DDTs}

The ratio of parent compound DDT to its metabolites DDD and DDE can be used to pin point the possible contaminating sources in the aquatic environment [28]. After the use of DDT, much of it slowly converted to DDE and DDD under aerobic and anaerobic conditions, respectively [29, 30]. Hence, the ratio between the DDT and DDE + DDD indicates recent or historic use of DDTs and biotransformation of the DDT [31]. A ratio of DDT to DDD + DDE much greater than 1 indicates fresh use of DDT; however, a small ratio indicates historical DDT use [32].

\subsection{Ecological Risk Assessment of the POPs}

The eco-toxicological risk assessment of POPs in prawn samples was evaluated using sediment quality guidelines (SQGs). SQGs are based on pollutant concentrations to harmful effects on sediment dwelling organisms or intended to be predictive of effects on sediment dwelling organisms [33]. In Pakistan, no such environmental guidelines have been established for POPs in aquatic sediments. Therefore, ecotoxicological effects of POPs in this study area were roughly evaluated by applying published sediment quality guidelines from Wisconsin's consensus based sediment quality guidelines (CBSQGs) [33].

\section{Results and Discussion}

Prawns were only found in upstream area of Nullah Aik and Nullah Palkhu, while no prawn species were found in mid, downstream or joining point areas of the 

Macrobrachium lamarrei from the Streams of Sialkot, Pakistan

two Nullahs. Only five out of 11 pesticide residues were detected on the basis of retention time by GC-ECD in the prawns collected from the upstream area of sampling. The detected pesticide residues were $\beta$-HCH, Lindane, DDD, 2,4-DDT and 4,4-DDT. The concentrations of detected pesticides were quantified on the basis of their peak area by external standard method. The results showed that the concentrations of $\beta-\mathrm{HCH}$, Lindane, DDD, 2,4-DDT and 4,4-DDT were $77.46,81.94,40.88,334.63$ and $417.21 \mu \mathrm{g} / \mathrm{kg}$, respectively, on a dry weight basis as shown in Fig. 2. Study area was divided in three zones-upstream, midstream and downstream. Zone 1 (upstream) is an area where only agricultural activities are being performed, and there are no industries, public places or simply towns or cities, esthetically it is a beautiful area with good vast area, clean air and crystal clear water. While, the zone 2 (midstream) is area of Sialkot city which is an industrial city of Pakistan and has variety of industries, effluents, pollutants and toxicants from industries, civic and municipal pollution being incorporated in water bodies flowing through the city; so due to plenty of toxic material and pollution, no prawn was captured or observed in this zone. In zone 3 areas (downstream) where industries or human population is less, but has polluted water as well, because there is no significant dilution of water, water quality is poor like midstream area; so in this area, no single prawn captured or observed. Prawn only sampled from zone 1, as it is industry or human population free area. Anthropogenic activity severely affects the water quality in upstream. Prawn samples contain different organic compounds, but overall water quality was ideal for these aquatic organisms, as many fish species and other aquatic organisms were also observed in upstream. Due to organic compounds persistent in nature, the compounds detected in the samples may be bio-accumulated in this species of prawn from local agricultural area, as these compounds have been used in this area previously, beside this zone 1 or upstream receive water from Indian-held Kashmir, the area of Jammu; so these compounds in zone 1 may be transported to this area by flowing these streams from Indian-held Kashmir (Jammu) to Sialkot which is study area and can bio-accumulate this species.

\subsection{Compositional and Isomeric Ratio Analysis}

To find out different sources of POPs contamination in study area, $\alpha-\mathrm{HCH} / \gamma-\mathrm{HCH}$ ratio was calculated to check whether their usage was recent or historic, as well as ratio of DDT to DDD + DDE was

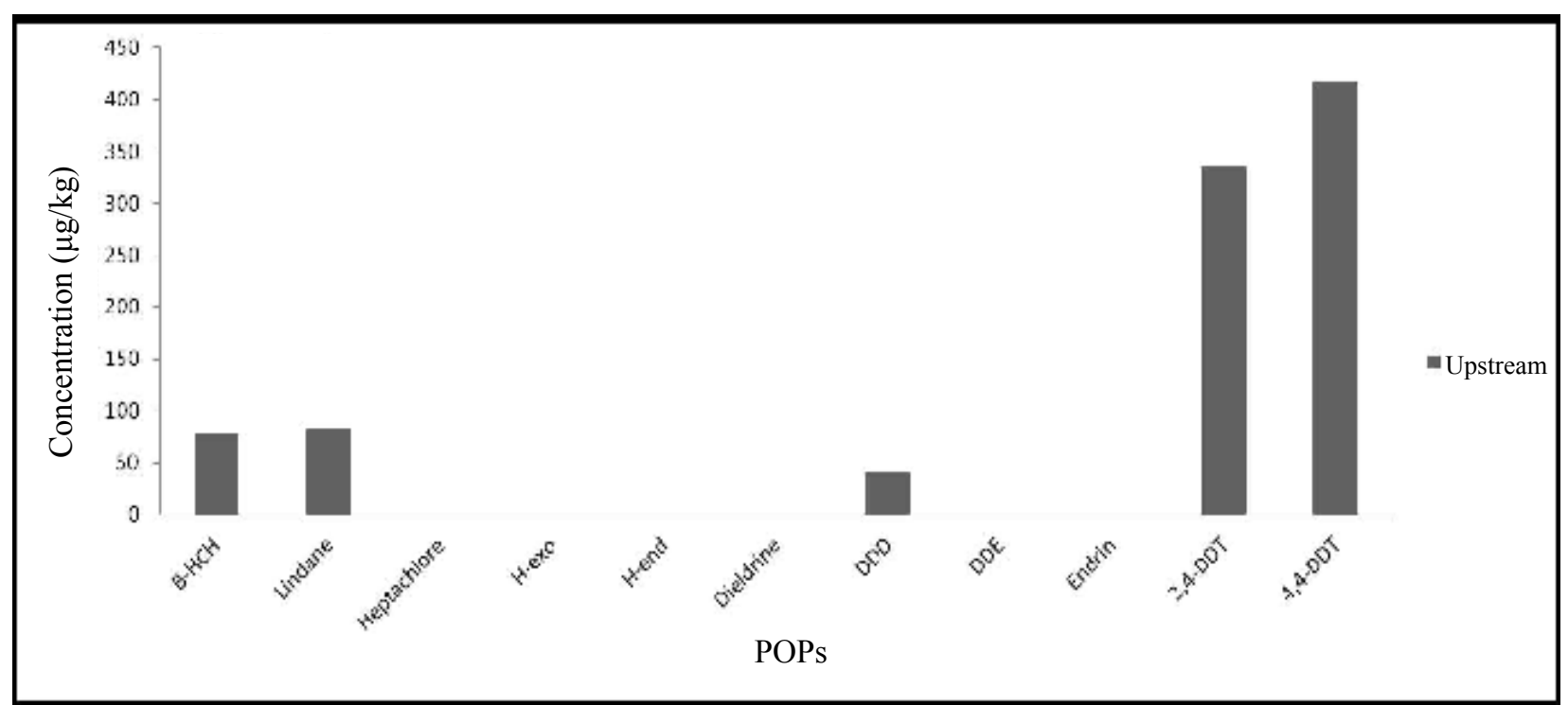

Fig. 2 Concentration of POPs in Macrobrachium lamarrei (prawn) in upstream of Nullah Aik and Nullah Palkhu at Sialkot district, Pakistan. 
Table 1 Threshold effect of concentration hazard quotients (TEC-HQ) for POPs.

\begin{tabular}{llll}
\hline POPs & TEC $(\mu \mathrm{g} / \mathrm{kg})$ & Concentration $(\mu \mathrm{g} / \mathrm{kg})$ & TEC-HQ \\
\hline$\alpha$-HCH & 6.00 & 77.46 & $12.91^{*}$ \\
$\gamma$-HCH (Lindane) & 3.00 & 81.94 & $27.31^{*}$ \\
DDD & 4.90 & 40.88 & $8.34^{*}$ \\
$2,4-D D T$ & 4.20 & 334.63 & $79.67^{*}$ \\
$4,4-D D T$ & 4.20 & 417.21 & $99.34^{*}$ \\
\hline Total & 21.30 & 952.12 & $44.70^{*}$ \\
\hline
\end{tabular}

${ }^{*}$ indicates TEC-HQ $>1$.

Table 2 Possible effect of concentration hazard quotients (PEC-HQ) for POPs.

\begin{tabular}{llll}
\hline POPs & PEC $(\mu \mathrm{g} / \mathrm{kg})$ & Concentration $(\mu \mathrm{g} / \mathrm{kg})$ & PEC-HQ \\
\hline$\alpha$-HCH & 100.00 & 77.46 & 0.77 \\
$\gamma$-HCH (Lindane) & 5.00 & 81.94 & $16.40^{*}$ \\
DDD & 28.00 & 40.88 & $1.46^{*}$ \\
$2,4-D D T$ & 63.00 & 334.63 & $5.31^{*}$ \\
$4,4-D D T$ & 63.00 & 417.21 & $6.62^{*}$ \\
\hline Total & 259.00 & 952.12 & $3.68^{*}$ \\
\hline
\end{tabular}

${ }^{*}$ indicates TEC-HQ $>1$.

evaluated. In the present study, the ratio of $\alpha-\mathrm{HCH} / \gamma-\mathrm{HCH}$ for prawn samples was 0.95 , which indicated an input of technical $\mathrm{HCH}$ and long range transport, while the ratio of DDT/(DDD + DDE) for prawn samples was estimated to be 10.2, which showed that there was a recent input of DDT to the study area.

\subsection{Ecological Risk Assessment of the POPs}

The ecological risks of POPs in the studied prawn samples were assessed on basis of the toxicity data of benthic organisms by applying published sediment quality guidelines from Wisconsin's consensus based SQGs. Relatively high risks, that is, concentration over its TEC, were observed for all five POPs, as shown in Table 1. Moreover, except $\alpha-\mathrm{HCH}$, the concentrations of the other four POPs exceeded their PEC values as shown in Table 2, indicating adverse ecological effects to benthic organisms. Tables 1 and 2, respectively, show the TEC-HQ and PEC-HQ of POPs in the studied prawn samples. The TEC-HQ of detected POPs were relatively high, particularly p,p'-DDT (79.67) and o,p'-DDT (99.34) as shown in Table 1. Similarly, the PEC-HQ values of detected POPs were more than 1 , depicting risk posed to health by them except $\alpha-\mathrm{HCH}(0.77)$.

\section{Conclusions}

The prawn (Macrobrachium lamarrei) was only captured/observed in upstream area of the study area (zone 1), which is agricultural zone and free form human population and industries, as well as spray of pesticides on different crops is common practice in this zone. The streams flowing in this area have pesticide residues, which were bio-accumulated in living biota of the streams. The rest two zones of the study area do not have any prawn sample, because of civic and industrial pollution in the stream water. Presence of some POPs residues in samples in upstream area (zone 1) of the study area clearly indicates that input of these POPs in upstream is from its catchment. It can be inferred from the present study that the levels of POPs residues in prawn are significant and quite high, and pose a threat to human health and wild life. This also indicates that the use of POPs in the catchment area is still going on without any proper management. It is the need of hour to stop indiscriminate use of POPs in agriculture, industries and human inhabitation to save the living biota from harmful pesticide residues. 

Macrobrachium lamarrei from the Streams of Sialkot, Pakistan

\section{References}

[1] Jacob, J., and Jacob, C. 2013. "Review of Environmental and Human Exposure to Persistent Organic Pollutants." Asian Social Science 9 (11): 107-20.

[2] Jones, K. C., and De Voogt, P. 1999. "Persistent Organic Pollutants (Pops): State of the Science." Environ. Pollut. 100 (1-3): 209-21.

[3] Lu, X., Chen, C., Zhang, S., Hou, Z., and Yang, J. 2013. "Concentration Levels and Ecological Risks of Persistent Organic Pollutants in the Surface Sediments of Tianjin Coastal Area, China." The Scientific World Journal. doi: 10.1155/2013/417435.

[4] Harrad, S., Ibarra, C., Robson, M., Melymuk, L., Zhang, X., Diamond, M., and Douwes, J. 2009. "Polychlorinated Biphenyls in Domestic Dust from Canada, New Zealand, United Kingdom and United States: Implications for Human Exposure." Chemosphere 76 (2): 232-8.

[5] Wu, H., Bertrand, K. A., Choi, A. L., Hu, F. B., Laden, F., Grandjean, P., and Sun, Q. 2013. "Persistent Organic Pollutants and Type 2 Diabetes: A Prospective Analysis in the Nurses' Health Study and Meta-Analysis." Environ. Health Perspect. 121 (2): 153-61.

[6] Ruzzin, J., Petersen, R., Meugnier, E., Madsen, L., Lock, E. J., Lillefosse, H., Ma, T., Pesenti, S., Sonne, S. B., Marstrand, T. T., Malde, M. K., Du, Z. Y., Chavey, C., Fajas, L., Lundebye, A. K., Brand, C. L., Vidal, H., Kristiansen, K., and Frøyland, L. 2010. "Persistent Organic Pollutant Exposure Leads to Insulin Resistance Syndrome." Environ. Health Perspect. 118 (4): 465-71.

[7] Enan, E., and Matsumura, F. 1994. “2,3,7,8-Tetrachlorodibenzo-p-Dioxin (TCDD)-Induced Changes in Glucose Transporting Activity in Guinea Pigs, Mice and Rats in Vivo and in Vitro." J. Biochem. Toxicol. 9 (2): 97-106.

[8] Jensen, S., Johnels, A. G., Oilson, M. L., and Otterlind, G. 1969. "DDT and PCB in Marine Animals from Swedish Waters.” Nature 224 (5216): 247-50.

[9] Pakistan Environmental Protection Agency. 2003. Inventory of Persistent Organic Pesticides "Punjab".

[10] Honnen, W., Rath, K., Schlegel, T., Schwinger, A., and Frahne, D. 2001. "Chemical Analyses of Water, Sediment and Biota in Two Small Streams in Southwest Germany." Journal of Aquatic Ecosystem Stress and Recovery 8 (3-4): 195-213.

[11] Majewski, M. S., and Capel, P. D. 1995. Pesticides in the Atmosphere: Distribution, Trends and Governing Factors. Open-File Report, US Geological Survey, Earth Science Information Center.

[12] Sullivan, D. J., and Richards, K. D. 1996. "Pesticides in Streams of the Western Lake Michigan Drainages, Wisconsin and Michigan, 1993-1995." US Geological
Survey Fact Sheet FS-107-96.

[13] Ferrari, M. J., Ator, S. W., Blomquist, J. D., and Dysart, J. E. 1997. Pesticides in Surface Water of the Mid-Atlantic Region. USGS Water-Resources Investigations Report.

[14] Dutta, H. M., Richmonds, C. R., and Zeno, T. 1993. "Effects of Diazinon on the Gills of Bluegill Sunfish Lepomis macrochirus." J. Environ. Pathol. Toxicol. Oncol. 12 (4): 219-27.

[15] Sarkar, U. K., Basheer, V. S., Singh, A. K., and Srivastava, M. 2003. "Organochlorine Pesticides Residues in Water and Fish Samples: First Report from Rivers and Streams of Kumaon Himalayan Region, India." Bulletin of Environmental Contamination and Toxicology 70 (3): 485-93.

[16] Shukla, O. P., Omkar, and Kulshrestha, A. K. 1998. Pesticides, Man and Biosphere, 1st ed.. New Dilhi, India: Ashish Publisher, 225-66.

[17] Liu, A. X., Lang, Y. H., Xue, L. D., Liao, S. L., and Zhou, H. 2009. "Probabilistic Ecological Risk Assessment and Source Apportionment of Polycyclic Aromatic Hydrocarbons in Surface Sediments from Yellow Sea." Bulletin of Environmental Contamination and Toxicology 83 (5): 681-7.

[18] Burreau, S., Zebühr, Y., Broman, D., and Ishaq, R. 2006. "Biomagnification of PBDEs and PCBs in Food Webs from the Baltic Sea and the Northern Atlantic Ocean." Science of the Total Environment 366 (2-3): 659-72.

[19] Gewurtz, S. B., Lazar, R., and Haffner, G. D. 2000. "Comparison of Polycyclic Aromatic Hydrocarbon and Polychlorinated Biphenyl Dynamics in Benthic Invertebrates of Lake Erie, USA.” Environmental Toxicology and Chemistry 19 (12): 2943-50.

[20] Bell, J. D., Steffe, A. S., and Westoby, M. 1988. "Location of Sea-Grass Beds in Estuaries: Effects on Associated Fish and Decapods." J. Exp. Mar. Biol. Ecol. 122 (2): 127-46.

[21] Sharma, A., and Subba, B. R. 2005. "General Biology of Freshwater Prawn, Macrobrachium lamarrei (H. Milne-Edwards) of Biratnagar, Nepal." Our Nature 3 (1): 31-41.

[22] Doong, R. A., Peng, C. K., Sun, Y. C., and Liao, P. L. 2002. "Composition and Distribution of Organochlorine Pesticide Residues in Surface Sediments from the Wu-Shi River Estuary, Taiwan." Marine Pollution Bulletin 45: 246-53.

[23] Qiu, X. H., Zhu, T., Li, J., Pan, H. S., Li, Q. L., Miao, G. F., and Gong, J. C. 2004. "Organochlorine Pesticides in Air around the Taihu Lake, China." Environ. Sci. Technol. 38 (5): 1368-74.

[24] Zhou, R. B., Zhu, L. Z., Yang, K., and Chen, Y. Y. 2006. "Distribution of Organochlorine Pesticides in Surface Water and Sediments from Qiantang River, East China." 

Macrobrachium lamarrei from the Streams of Sialkot, Pakistan

Journal of Hazardous Materials 137 (1): 68-75.

[25] Lane, D. A., Johnson, N. D., Hanley, M. J. J., Schoeder, W. H., and Ord, D. T. 1992. "Gas- and Particle-Phase Concentrations of $\alpha$-Hexachlorocyclohexane, $\gamma$-Hexachlorocyclohexane and Hexachlorobenzene in Ontario Air." Environ. Sci. Technol. 26 (1): 126-33.

[26] Iwata, H., Tanabe, S., Sakai, N., and Tatsukawa, R. 1993. "Distribution of Persistent Organochlorines in the Oceanic Air and Surface Seawater and the Role of Ocean on Their Global Transport and Fate." Environ. Sci. Technol. 27 (6): 1080-98.

[27] Willet, K. L., Ulrich, E. M., and Hites, R. A. 1998. "Differential Toxicity and Environmental Fates of Hexachlorocyclohexane Isomers." Environ. Sci. Technol. 32 (15): 2197-207.

[28] Guo, Y., Yu, H. Y., and Zheng, E. Y. 2009. "Occurrence, Source Diagnosis and Biological Effect Assessment of DDT and Its Metabolites in Various Environmental Compartments of the Pearl River Delta, South China: A Review.” Environmental Pollution 157 (6): 1753-63.

[29] Baxter, R. M. 1990. "Reductive Dechlorination of Certain
Chlorinated Organic Compounds by Reduced Hematin Compared with Their Behavior in the Environment." Chemosphere 21 (4-5): 451-8.

[30] Aislabie, J. M., Richards, N. K., and Boul, H. L. 1997. "Microbial Degradation of DDT and Its Residues: A Review." New Zealand Journal of Agricultural Research 40: 269-82.

[31] Qian, Y., Zheng, M. H., Zhang, B., Gao, L. R., and Liu, W. B. 2006. "Determination and Assessment of HCHs and DDTs Residues in Sediments from Lake Dongting, China." Environ Monit. Assess. 116: 157-67.

[32] Ma, X., Ran, Y., Gong, J., and Zou, M. 2008. "Concentrations and Inventories of Polycyclic Aromatic Hydrocarbons and Organochlorine Pesticides in Watershed Soils in the Pearl River Delta, China." Environ Monit. Assess. 145: 453-64.

[33] Wisconsin Department of Natural Resources. 2003. "Consensus-Based Sediment Quality Guidelines (SQGs)." Accessed September 2007. https://archive.epa.gov/reg5sfun/ecology/web/html/screen ingbench.html. 